\title{
Outcome of Corneal Limbal Stem Cell Transplant in the Treatment of Partial and Total Limbal Stem Cell Deficiency - A Middle East Experience
}

\section{Ammar M. Al-Mahmood ${ }^{1 *}$, Samar A. Al-Swailem¹, Abdullah A. Al-Assiri, ${ }^{1,2}$, Ghada Y. Al Bin Ali² and Sabah S. Jastaneiah}

${ }^{1}$ Division of Anterior Segment, King Khaled Eye Specialist Hospital, Riyadh, Kingdom of Saudi Arabia

${ }^{2}$ Department of Ophthalmology, Bahrain Defense Force Hospital, Kingdom of Bahrai

\begin{abstract}
Aim: To evaluate the outcomes of Conjunctival Limbal Autograft (CLAU) and Conjunctival Limbal Allograft (CLAL) transplants for the treatment of partial or total Limbal Stem Cell Deficiency (LSCD).

Methods: Retrospective, cohort study. All eyes treated with limbal stem cell transplant (LSCT) that had 1 year follow-up or more were included. Visual success was measured by improvement in VA post operatively. Surgical success was defined as maintaining a healthy clear corneal surface post operatively.

Results: There were 8 autolimbal and 9 allolimbal transplants. Of the latter, 8 were from living related donors (Lr-CLAL) and one was Keratolimbal Allograft (KLAL). Fifteen eyes had total LSCD and two eyes had partial LSCD. Primary diagnosis included combined chemical \& thermal Injury burn $(n=13)$, vernal keratoconjunctivits $(n=2)$, herpes simplex infection $(n=1)$ and idiopathic $(n=1)$. Mean post operative follow-up was $50.65 \pm 34.68$ months (range 12 108 months). CLAU was successful in 7 out of 8 eyes (87.5\%). Mean VA improved from $0.1 \pm 0.12$ to $0.44 \pm 0.28$ (measured in decimal fraction). CLAL was successful in 2 out of 9 eyes (22.2\%). Mean VA improved from $0.03 \pm 0.04$ to $0.10 \pm 0.22$. All eyes with CLAU achieved re-epithelialization and maintained an intact epithelium. Eyes with CLAL achieved re-epithelialization and maintained an intact epithelium in $66.7 \%$ (6).
\end{abstract}

Conclusion: LSCT is an effective modality of treatment in patients with LSCD. CLAU transplant and absence of post operative complications were associated with statistically higher success rate. Younger patients and wet ocular surface had more favorable outcome.

Keywords: Stem cell deficiency; Stem cell transplantation; Conjunctival limbal autograft; Conjunctival limbal allograft; Keratolimbal allograft

\section{Introduction}

The corneal epithelial cells undergo constant renewal and regeneration. Cells from the surface are desquamated and replaced by proliferating basal epithelial cells from the periphery. The cells undergo vertical and horizontal movements. This state of dynamic equilibrium is maintained by a sub-population of cells, the Limbal Stem Cells (LSCs), residing within the palisades of Vogt at the limbus. The basal limbal epithelium provides the source for corneal epithelial regeneration [1-2]. In patients with complete limbal stem cell destruction, corneal conjunctivalization accompanied by the invasion of goblet cells is inevitable [3]. In unilateral diseases; autologous material harvested from the healthy eye may be used. In bilateral cases, allogeneic material must be transplanted [4-7].

The purpose of this study was to present a retrospective analysis of the outcome of conjunctival limbal graft transplantation for ocular surface reconstruction in patients with partial or total limbal stem cell deficiency (LSCD). The influence on surgical outcome of many variables, including cause of LSCD, dry eye syndrome, systemic immunosuppressant, age of patients, time of surgery, and associated keratoplasty, were analyzed.

\section{Materials and Methods}

This study was approved by the Institutional Review Board at King Khaled Eye Specialist Hospital. The Medical records of all patients with partial or total LSCD who required LSCT at our tertiary eye center between November 1998 and December 2007 were reviewed. A computer-based search of inpatient records was generated by cross-referencing coded discharge information to obtain a list of eligible patients. Patients included in this study had corneal LSCD, identified clinically by the presence of late fluorescein staining, loss of limbal palisade of Vogt, superficial vascularization or complete conjunctivalization of the cornea. All these patients required limbal stem cell transplant (LSCT) as part of their treatment. Specific data collected included demographics, pre-operative, operative and postoperative data. Pre-operative data included the following: date of LSCD diagnosis, cause of LSCD, type of diagnosis (clinical or Lab based), extent of LSCD, preoperative Best Corrected Visual Acuity (BCVA), previous ocular disorders or surgeries, pre-operative medications, pre-operative Intraocular Pressure (IOP), extent of corneal vascularization, and wither HLA and ABO matching was done prior to surgery. Operative data included the following: date of surgery, type of anesthesia, source of the graft (conjunctival limbal autograft (CLAU), living related donor's conjunctival limbal autograft (Lr-CLAL), or keratolimbal allograft (KLAL), donor information if applicable, size and location of the graft, type of suturing, associated surgical procedures, and presence of intra-operative complications. Post-operative data included records of VA, post-operative complications, topical and systemic post operative

*Corresponding author: Ammar M. Al-Mahmood, MD, FRCS (Glasg.), Division of Anterior Segment \& Uveitis, King Khaled Eye Specialist Hospital, Riyadh, Kingdom of Saudi Arabia, P. O. Box 7191 Riyadh 11462, E-Mail: dr3mmar@yahoo.com

Received April 14, 2012; Accepted May 02, 2012; Published May 04, 2012

Citation: Al-Mahmood AM, Al-Swailem SA, Al-Assiri AA, Al Bin Ali GY, Jastaneiah SS (2012) Outcome of Corneal Limbal Stem Cell Transplant in the Treatment of Partial and Total Limbal Stem Cell Deficiency - A Middle East Experience. J Stem Cell Res Ther 2:121. doi:10.4172/2157-7633.1000121

Copyright: (c) 2012 Al-Mahmood AM, et al. This is an open-access article distributed under the terms of the Creative Commons Attribution License, which permits unrestricted use, distribution, and reproduction in any medium, provided the original author and source are credited. 
Citation: Al-Mahmood AM, Al-Swailem SA, Al-Assiri AA, Al Bin Ali GY, Jastaneiah SS (2012) Outcome of Corneal Limbal Stem Cell Transplant in the Treatment of Partial and Total Limbal Stem Cell Deficiency - A Middle East Experience. J Stem Cell Res Ther 2:121. doi:10.4172/21577633.1000121

Page 2 of 3

medications, side effects of medications if present, post-operative procedures, date of last visit, BCVA in the last visit, mean period of ambulatory vision, the clinical findings during the last visit and wither a keratoplasty or repeated LSCT was required.

Visual success was measured by improvement in Visual Acuity (VA) in the operated eye during the follow-up period. Surgical success was defined as maintaining a healthy clear corneal surface following LSCT until last follow-up. Patients unable to perform Snellen VA test due to either young age or mental handicap were excluded. Patients with a follow up period of less than 12 months were also excluded. The Snellen VAs is converted to decimal fraction for statistical analyses. For Snellen VA less than 20/400, counting fingers (CF; 0.025), hand motions (HM; 0.0125), light perception (LP; 0.006), and no light perception (NLP; 0.0) were used.

\section{Surgical technique}

In case of total LSCD two types of LSCT were performed by nine different experienced anterior segment surgeons, CLAU and CLAL. In cases of CLAL, grafts consisted of 3 clock hours of superior and inferior limbus including $1 \mathrm{~mm}$ of peripheral cornea and $3 \mathrm{~mm}$ of adjacent conjunctiva was obtained from the donor. On the recipient eye, the fibrovascular pannus was removed from the recipient cornea. Grafts were sutured to the 12 and 6 o'clock positions of the recipient. Similar procedure was applied in cases of CLAU. The source of the graft in these cases was the contralateral healthy eye. KLAL donor tissue consisted of the entire limbus with $1 \mathrm{~mm}$ of peripheral cornea. In case of partial LSCD graft consisted of 3 clock hours of the limbus including $1 \mathrm{~mm}$ of peripheral cornea and $3 \mathrm{~mm}$ of adjacent conjunctiva were obtained from the contralateral healthy eye and sutured to the area of deficiency.

Statistical analysis was carried out using SPSS 15.0. Fisher's exact test was utilized to calculate success significance. CLAU and CLAL, were analyzed separately in terms of age, gender, cause of LSCD, dryness, and presence of post operative complications.

\section{Results}

Fourteen patients (17 eyes) were included in our study as they were suffering from LSCD requiring LSCT. The primary diagnoses included combined chemical-thermal burn (thirteen eyes, 76.5\%), VKC (Two eyes, $11.8 \%$ ), herpetic infection (one eye, $5.9 \%$ ), and idiopathic LSCD (one eye, 5.9\%). All eyes had the procedure once except 1 eye that had the procedure twice. Of the 17 procedures, $47.1 \%$ (8) were CLAU, $47.1 \%$ (8) were CLAL from a first degree family relative, and $5.9 \%$ (1) were KLAL. LSCT was combined with Penetrating Keratoplasty (PKP) and Amniotic Membrane Transplant (AMT) in 2 eyes, and with superficial keratectomy combined with AMT in 13 eyes. In 2 cases, limbal stem cell transplantation was not combined with any other surgical procedure. Six eyes required PKP after LSCT. LSCT was preceded by PKP combined with lid repair in 4 eyes, AMT in 3 eyes, and one eye had penetrating keratoplasty with glaucoma surgery. The remaining 8 eyes had no previous record of ocular surgery. Corneal dryness was reported in $76.5 \%(\mathrm{n}=13)$ cases prior to LSCT.

The mean age at time of surgery was $27.76 \pm 12.59$ years (range, 8-65 years); nine cases were females. Mean post operative follow-up period was $50.65 \pm 34.68$ months (range 12-108 months). Fifteen eyes had total LSCD. The remaining two had partial LSCD. Three cases had glaucoma prior to LSCT. IOP was controlled with topical antiglaucoma medications in all those three cases. Mean IOP prior to LCST was $14.29 \pm 3.42 \mathrm{mmHg}$.
All patients with CLAU showed complete re-epithelialization of the cornea. A healthy corneal epithelium was maintained until last follow-up in all eyes. Two of those eyes developed superficial corneal neovascularization. Visual success was achieved in $87.5 \%$ (7) of eyes (Figure 1). The mean VA have improved from $0.1 \pm 0.12$ to $0.44 \pm 0.28$.

In CLAL patients, complete re-epithelialization of the cornea was achieved in $66.7 \%$ of the eyes (6). In the last follow-up, $55.5 \%$ (5) eyes developed complete conjunctivalization of the cornea and the remaining $44.4 \%$ (4) developed superficial neovascularization despite an intact corneal epithelium. Visual success was only achieved in $22.2 \%$ (2) eyes (Figure 2). 33.3\% (3) of eyes maintained their VA as prior to LSCT and $44.4 \%$ (4) suffered a drop in their VA. The mean VA have improved from $0.03 \pm 0.04$ to $0.10 \pm 0.22$.

Both eyes of partial LSCD underwent CLAU and were successful in terms of VA improvement and ocular surface stability.

\section{Discussion}

Reconstruction and restoration of the ocular surface of eyes with either partial or total LSCD is a challenging problem. In unilateral disease the option of a CLAU obtained from the contralateral eye has been a well-established option [8-10]. Treatment of bilateral disease depends on transplantation of allograft tissue from a living related donor or from a cadaveric tissue. The graft would later be applied to the affected eye wither directly or following expansion over a suitable substrate.

Outcomes after CLAL transplantation have been reported with

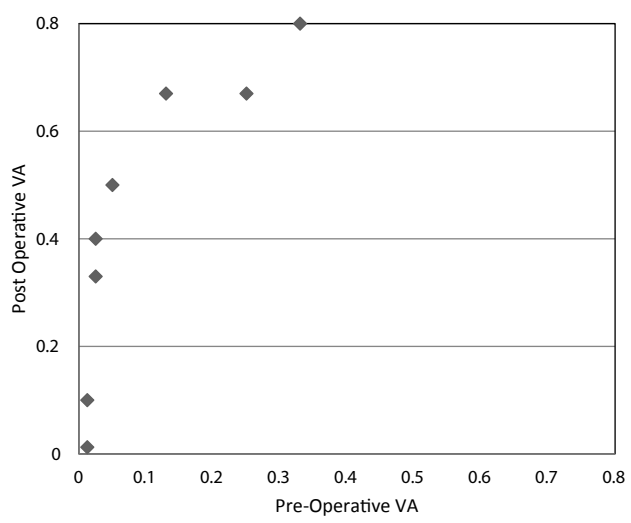

Figure 1: Comparison of visual acuity in decimals before and after autolimbal stem cell transplant.

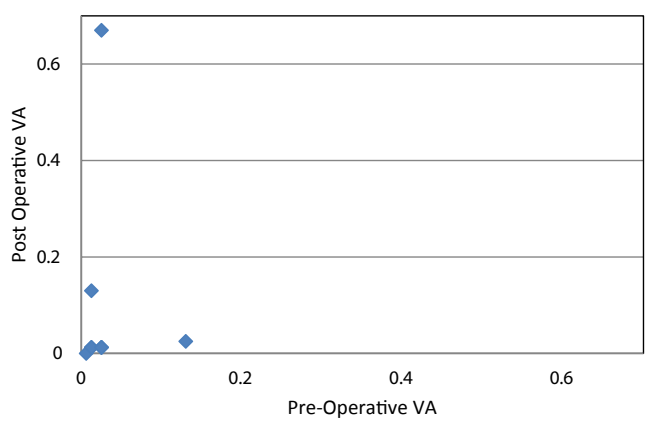

Figure 2: Comparison of visual acuity in decimals before and after allolimbal stem cell transplant. 
Citation: Al-Mahmood AM, Al-Swailem SA, Al-Assiri AA, Al Bin Ali GY, Jastaneiah SS (2012) Outcome of Corneal Limbal Stem Cell Transplant in the Treatment of Partial and Total Limbal Stem Cell Deficiency - A Middle East Experience. J Stem Cell Res Ther 2:121. doi:10.4172/21577633.1000121

encouraging results in short term follow ups [11]. Long term follow ups exceeding one year showed variable results. Daya et al. [12] reported $80 \%$ successful re-epithelization and 50\% improved final VA in 10 eyes with a mean follow up of 26.2 months. Reinhard et al. [13] reported $65 \%$ success in term of central graft clarity after five years postoperatively. A failure after a period of two years was reported by Ilari et al. [14]. Solomon et al. [15] reported an overall visual success of 56.3\% in 39 eyes. Tsubota et al. [16] and Samson et al. [17] reported similar results. The longest follow up was reported by Miri et al. [18] were follow ups extended up to 119 months. Ocular surface stability was seen in $82 \%$ of 27 eyes. An improved mean VA was also noted.

We report a long term follow up that extends to 108 months. In term of visual success our CLAU success rate is comparable with others (87.5\%) $[9,10]$. The CLAL success $(22.2 \%)$ was lower than reported in the literature. This reflects the need of proper HLA typing prior to donor's selection and the use of systemic immunosuppressants post operatively, the later was applied in a single patient whom underwent CLAL. Systemic steroids and cyclosporine were used resulting in a successful procedure. The duration between diagnosis and surgical intervention in the form of LSCT was found to be significant. Statistically higher procedure success was associated with CLAU transplant $(\mathrm{p}=0.012)$ and absence of post operative complications $(\mathrm{p}=0.044)$. Eyes that had their LSCT 18 months or more following the diagnosis of LSCD have performed better $(\mathrm{p}=0.036)$. This could be explained that eyes received longer medical treatment prior to surgery are less likely to have inflammation; even subclinical; that would jeopardize the LSCT. Eyes with wet ocular surface ( $\mathrm{p}=0.053)$ and those younger than 18 years $(\mathrm{p}=0.053)$ had more favorable outcome.

Some factors were not found to be statically significant associated with the success or failure of LSCT. Those include: associated PKP at the time of LSCT ( $p=0.79)$, AMT at the time of LSCT ( $p=0.56)$, use of topical anti-glaucoma medications $(\mathrm{p}=0.5)$ and eyelid repair prior to $\operatorname{LSCT}(\mathrm{p}=0.75)$.

Ex-vivo expansion is becoming a successful procedure nowadays [19-21]. Its major advantage is minimal donor's tissue requirement which allows utilization of patients own LSCs even in cases of bilateral ocular injury with minimal survival of LSCs. Although exvivo expansion might be of choice for most cases, the procedure is considered expensive, time consuming and requires high expertise which renders it unavailable in most of institutes including ours.

In conclusion we think that LSCT is an effective modality of treatment in patients with LSCD. CLAU transplant, absence of post operative complications and longer diagnosis to LSCT duration are associated with statically higher success rate. Younger patients and wet ocular surface had more favorable responses.

\section{References}

1. Chen JJ, Tseng SC (1990) Corneal epithelial wound healing in partial limbal deficiency. Invest Ophthalmol Vis Sci 31: 1301-1314.

2. Huang AJ, Tseng SC (1991) Corneal epithelial wound healing in the absence of limbal epithelium. Invest Ophthalmol Vis Sci 32: 96-105.

3. Puangricharern V, Tseng SC (1995) Cytologic evidence of corneal diseases with limbal stem cell deficiency. Ophthalmology 102: 1476-1485.

4. Reinhard T, Sundmacher R, Spelsberg H, Althaus C (1999) Homologous penetrating central limbo-keratoplasty (HPCLK) in bilateral limbal stem cell insufficiency. Acta Ophthalmol Scand 77: 663-667.
5. Sundmacher R, Reinhard T (1996) Central corneolimbal transplantation under systemic ciclosporin A cover for severe limbal stem cell insufficiency. Graefes Arch Clin Exp Ophthalmol 234: S122-S125.

6. Dua HS, Azuara-Blanco A (1999) Allo-limbal transplantation in patients with limbal stem cell deficiency. $\mathrm{Br} \mathrm{J}$ Ophthalmol 83: 414-419.

7. Shimazaki J, Kaido M, Shinozaki N, Shimmura S, Munkhbat B, et al. (1999) Evidence of long-term survival of donor-derived cells after limbal allograft transplantation. Invest Ophthalmol Vis Sci 40: 1664-1668.

8. Kenyon KR, Tseng SC (1989) Limbal autograft transplantation for ocular surface disorders. Ophthalmology 96: 709-722.

9. Dua HS, Azuara-Blanco A (2000) Autologous limbal transplantation in patients with unilateral corneal stem cell deficiency. Br J Ophthalmol 84: 273-278.

10. Meallet MA, Espana EM, Grueterich M, Ti SE, Goto E, et al. (2003) Amniotic membrane transplantation with conjunctival limbal autograft for total limbal stem cell deficiency. Ophthalmology 110: 1585-1592.

11. Rao SK, Rajagopal R, Sitalakshmi G, Padmanabhan P (1999) Limba allografting from related live donors for corneal surface reconstruction. Ophthalmology 106: 822-828.

12. Daya SM, Ilari FA (2001) Living related conjunctival limbal allograft for the treatment of stem cell deficiency. Ophthalmology 108: 126-133.

13. Reinhard T, Spelsberg H, Henke L, Kontopoulos T, Enczmann J, et al. (2004) Long-term results of allogeneic penetrating limbo-keratoplasty in total limbal stem cell deficiency. Ophthalmology 111: 775-782.

14. Ilari L, Daya SM (2002) Long-term outcomes of keratolimbal allograft for the treatment of severe ocular surface disorders. Ophthalmology 109: 1278-1284.

15. Solomon A, Ellies P, Anderson DF, Touhami A, Grueterich M, et al. (2002) Longterm outcome of keratolimbal allograft with or without penetrating keratoplasty for total limbal stem cell deficiency. Ophthalmology 109: 1159-1166.

16. Tsubota K, Satake Y, Kaido M, Shinozaki N, Shimmura S, et al. (1999) Treatment of severe ocular-surface disorders with corneal epithelial stem-cell transplantation. N Engl J Med 340: 1697-1703.

17. Samson CM, Nduaguba C, Baltatzis S, Foster CS (2002) Limbal stem cell transplantation in chronic inflammatory eye disease. Ophthalmology 109: 862 868.

18. Miri A, Al-Deiri B, Dua HS (2010) Long-term outcomes of autolimbal and allolimbal transplants. Ophthalmology 117: 1207-1213.

19. Rama P, Matuska S, Paganoni G, Spinelli A, De Luca M, et al. (2010) Limba Stem-Cell Therapy and Long-Term Corneal Regeneration. N Engl J Med 363: 147-155.

20. Tsai RJ, Li LM, Chen JK (2000) Reconstruction of damaged corneas by transplantation of autologous limbal epithelial cells. N Engl J Med 343: 86-93.

21. Shimazaki J, Aiba M, Goto E, Kato N, Shimmura S, et al. (2002) Transplantation of human limbal epithelium cultivated on amniotic membrane for the treatment of severe ocular surface disorders. Ophthalmology 109: 1285-1290. 